\title{
Tear function tests in pregnant women with gestational diabetes mellitus
}

Kan $\mathrm{S}^{1}$, Acar $\mathrm{U}^{2}$, Kizilgul $\mathrm{M}^{3}$, Beyazyildiz $\mathrm{E}^{4}$, Cankaya $\mathrm{AB}^{2}$, Apaydin $\mathrm{M}^{3}$, Beysel $\mathrm{S}^{3}$, Ozbek $\mathrm{M}^{3}$, Delibasi $\mathrm{T}^{3,5}$

${ }^{1}$ Department of Endocrinology and Metabolism, Ankara Teaching and Research Hospital, Ankara, Turkey

2Department of Ophthalmology, Hacettepe University, Faculty of Medicine, Ankara,Turkey

${ }^{3}$ Department of Endocrinology and Metabolism, Diskapi Teaching and Research Hospital, Ankara, Turkey

${ }^{4}$ Department of Ophthalmology, Samsun Teaching and Research Hospital, Samsun, Turkey

${ }^{5}$ Department of Internal Medicine, School of Medicine (Kastamonu), Hacettepe University, Turkey

Gestational diabetes mellitus (GDM) is a disorder, which is described as impaired glucose tolerance, which firstly occurs first time during pregnancy. We aimed to evaluate the tear function tests in GDM.

Pregnant women with GDM and healthy pregnants who were matched in both age and gestational age, were enrolled into the study. The women with ocular or systemic disorders that may affect the tear function tests, and who use topical medications were excluded from the study. All of the pregnants answered the OSDI questionnaire; afterwards they underwent a detailed ophthalmic examination including Schirmer, tear break-up time (TBUT), tear film osmolarity (TFO), and ocular surface disease index (OSDI) score by the same ophthalmologist.

Forty-six pregnant with GDM whose mean age of $30.43 \pm 4.75$ years and 36 healthy pregnant whose mean age of $28.83 \pm 4.42$ years were enrolled into the study. The mean gestational ages were 25.80 \pm 1.61 weeks and $26.19 \pm 1.43$ weeks respectively. There were not statistically significant differences between two groups in terms of age and gestational age. The mean fast blood glucose and the mean $\mathrm{HbA} 1 \mathrm{c}$ levels were statistically significantly higher $(\mathrm{p}<0.001$, for each) in GDM group $(105.17 \pm 7.28$ $\mathrm{mg} / \mathrm{ml}$ and $5.57 \pm 0.50 \%)$ compared to healthy group $(70.17 \pm 6.54 \mathrm{mg} / \mathrm{ml}$ and $4.93 \pm 0.29 \%)$. The levels of Schirmer test, TBUT test, TFO and OSDI score were $11.20 \pm 4.93 \mathrm{~mm}, 5.59 \pm 2.16 \mathrm{sec}$, $309.65 \pm 14.80 \mathrm{mOsm} / \mathrm{L}$ and $9.59 \pm 9.69$ points in GDM group, and $12.33 \pm 5.33 \mathrm{~mm}, 5.67 \pm 2.68$ $\mathrm{sec}, 308.36 \pm 16.00 \mathrm{mOsm} / \mathrm{L}$ and $10.62 \pm 8.66$ points in healthy group. There were not statistically significant differences in any of the tear function tests between two groups.

To the best of our knowledge, there is no study in the literature about the affects of GDM on dry eye parameters. GDM seems to be no negative effects on tear function tests 